\title{
Comparisons as Predictors of People's Beliefs about the Importance of Changing Their Health Behaviors
}

\author{
Jane E. Miller ${ }^{*}$, Paul D. Windschitl ${ }^{1}$, Teresa A. Treat ${ }^{1}$ and Aaron M. Scherer ${ }^{2}$ \\ ${ }^{1}$ Department of Psychological and Brain Sciences, University of Iowa, Iowa City, IA, USA \\ ${ }^{2}$ Department of Internal Medicine, University of Iowa Hospitals and Clinics, Iowa City, IA, USA
}

This article is in press at the European Journal of Health Psychology.

This version of the article may not completely replicate the final authoritative version published in the European Journal of Health Psychology. It is not the version of record and is therefore not suitable for citation. Please do not copy or cite without the permission of the author(s) and without the final DOI for the published article.

*Correspondence concerning this article should be addressed to Jane E. Miller, Department of

Psychological and Brain Sciences, University of Iowa, Iowa City, IA 52242. Email: janemiller@uiowa.edu. 


\begin{abstract}
The current study tested relative strengths of different comparison beliefs for predicting people's self-assessments of whether they should increase their health-relevant behaviors (exercise, sleep, and fruit and vegetable consumption). Comparison beliefs relevant to three standards (perceived global, local, expert standards) were evaluated. Data were combined from three similar studies (total $N=744$ ) that had a cross-sectional, within-subject design. Participants completed importance-of-change scales regarding the three health behaviors and reported comparison beliefs and absolute behavior frequencies/amounts. Results were consistent across the three behaviors. Comparison beliefs predicted ratings of importance of changing one's behavior, even beyond what is predicted by reports of absolute behavior frequency. Expert comparisons were consistently most predictive above and beyond the absolute estimates and the other comparison standards. There was no evidence of a local dominance effect when examining local versus global comparisons. Comparison beliefs have unique utility for predicting people's perceived importance of changing their heath behavior. The fact that expert comparisons were consistently most predictive (and local comparisons the least) may have implications for interventions designed for encouraging behavior change.
\end{abstract}

Keywords: social comparisons, comparative information, self-information, health behaviors, judgment and decision-making 
Comparisons as Predictors of People's Beliefs about the Importance of Changing Their Health Behaviors

People's beliefs about the importance of changing their behavior can be a key determinant of actual behavior change. This is reflected in the theories of reasoned action and planned behavior (Ajzen, 1991; Fishbein and Ajzen, 1975). These theories posit that behavior or change of behavior is driven by intentions, which are driven by belief-based attitudes about the behavior-including beliefs about the wisdom and importance of the behavior/change (Ajzen, 1991; Albarracín, Johnson, Fishbein, \& Muellerleile, 2001; Conner \& Armitage, 1998; Fishbein \& Ajzen, 2010). A role of perceived importance is also posited in the transtheoretical model of behavior change. The model assumes that the route to behavior change starts when a person leaves the pre-contemplation stage, where a person is unware that their behavior is a problem for a health outcome, which essentially means they do not see any importance for changing their behavior (Marshall \& Biddle, 2001; Prochaska, DiClemente, \& Norcross, 1992; Prochaska, Redding, \& Evers, 2015; Prochaska \& Velicer, 1997). Finally, the role of perceived importance of behavior change is also reflected in the health counseling technique of motivational interviewing, during which a person is asked why and to what extent they think it is important to change their health behaviors. These questions are used to strengthen the perceived importance of, and in turn, intention to change behavior (Burke, Arkowitz, \& Menchola, 2003; DiClemente \& Velasquez, 2002; Miller \& Rollnick, 2002, 2009).

Beyond being proposed as having a theoretical role, perceptions of the importance of changing one's behavior have also been empirically examined as a predictors of behavior change. In studies involving the theories of reasoned action and planned behavior (Ajzen, 1991; Fishbein and Ajzen, 1975), measures of attitudinal components that typically include items on the wisdom and importance of behavior change have been shown to be directly related to both intentions and actual changes in a variety of behaviors, including three that are germane to the 
present project: exercise (e.g., Courneya \& McAuley, 1995; Hagger, Chatzisarantis, \& Biddle, 2002; Hausenblas, Carron, \& Mack, 1997), amount of sleep (e.g., Knowlden, Sharma, \& Bernard, 2012; Lao, Tao, \& Wu, 2016; Tagler, Stanko, \& Forbey, 2017), and healthy eating (e.g., Blanchard et al., 2009a; Blanchard et al., 2009b; Conner, Norman, \& Bell, 2002). In research involving either the transtheoretical-model or motivated-interviewing perspectives, readiness to change - measured as a continuous factor - has predicted both intentions and actual behavior change (e.g., King, Marcus, Pinto, Emmons, \& Abrams, 1996; La Brie, Quinlan, Schiffman, \& Earleywine, 2005; Park \& Gaffey, 2007). Critically, readiness to change is conceptualized as two factors, confidence in change and perceived importance of change (Miller \& Rollnick, 2002; Rollnick, Mason, \& Butler, 1999; Van Leer, Hapner, \& Connor, 2008; see also Rollnick, 1998).

Given that beliefs about the importance of changing one's behavior can be a precursor to eventual behavior change, this raises questions about the factors that predict when people believe they should change behavior. For example, when would people think they exercise enough vs. need to exercise more? There are a variety of approaches to answering that question. For example, there are individual differences in people's health consciousness that would predict perceptions of whether they exercise enough (Yun \& Silk, 2011), and people recently viewing health communications about the importance of exercise might be especially likely to think they need to exercise more (Gray \& Harrington, 2011).

The present work focuses on a specific set of potential predictors of people's beliefs about the importance of increasing a healthy behavior. These potential predictors are people's beliefs about how much they already do the behavior and how that amount/frequency compares to different standards. More specifically, we examined the relative predictive power of four amount-relevant beliefs: 
1. Self-reports about absolute behavior frequency/amount (e.g., hours spent exercising)

2. Beliefs about how self-reported behavior frequency compares to an average person's behavior frequency (global comparison).

3. Beliefs about how self-reported behavior frequency compares to a peer's behavior frequency (local comparison).

4. Beliefs about how self-reported behavior frequency compares to perceived expert recommendations of how often one should engage in those behaviors (expert comparison).

Presumably, these beliefs would be positively intercorrelated. People who, on the basis of their self-report, do a lot of a given behavior, such as hours spent exercising, necessarily have an objectively higher comparison status. Their higher comparison status may also be at least partially reflected in their subjective estimates of how their status compares with global, local, and expert standards. Also, the zero order correlations of each of these beliefs with the degree to which people think they should change their health-relevant behavior would presumably be negative. That is, people who, on the basis of their self-report, do a lot of a given healthy behavior, would be the least inclined to think they need to increase that behavior (e.g., Carver $\&$ Scheier, 1999; Manning, 2009; Neighbors, Larimer, \& Lewis, 2004; Rimal \& Real, 2005).

Our main interest, however, was in the relative predictive power of the four queried beliefs. If the intercorrelations among the four beliefs are not exceedingly high, which one(s) are most predictive of people's perceptions of the importance of changing their behavior? Logically, absolute assessments of current health behavior might be the best predictor. Absolute levels of a health behavior are more objectively relevant to people's outcomes than is social comparative standing. For example, a person's vulnerability to heart disease may be high if they rarely exercise, irrespective of whether their peers exercise more or less than they do. This objective relevance of absolute amounts might be implicitly or explicitly appreciated by people, which 
could cause beliefs about absolute amounts to be more predictive of when people think they should increase a health behavior.

With that said, beliefs about how one's health behavior compares to what an expert recommends might be as good as or better at predicting importance-of-change beliefs. Expert recommendations have been shown to increase positive health behaviors such as getting vaccinated against the flu (Cummings, Jette, Brock, \& Haefner, 1979) and eating more fruits and vegetables (Larson \& Story, 2009), as well as decrease negative health behaviors such as bingedrinking (Michie et al., 2012) and smoking cigarettes (Prochaska, Velicer, Prochaska, Delucchi, \& Hall, 2006). The predictive value of expert recommendations has logical appeal: a person who rarely exercises may focus more on how the number of hours they exercise is less than the number of hours experts recommend, rather than the stand-alone value of their absolute estimate.

Despite the logical appeal of the idea that absolute beliefs and expert comparisons should matter most to people and therefore would be most predictive of importance-of-change beliefs, there is also a strong basis on which to hypothesize that social comparison information could have a strong influence. The concept of descriptive norms suggests that people's perceptions about how often others perform certain behaviors (e.g., how often a person thinks someone exercises) are predictive of the perceiver's behaviors (Lapinski \& Rimal, 2005; Priebe \& Spink, 2011; Rimal \& Real, 2005). There is also extensive research investigating the influence of social comparisons in the context of health-relevant behavior (e.g., Gibbons \& Gerrard, 1997; Jemmott, Ditto, \& Croyle, 1986; Klein, 1997, 2003; Mahler, 2018; Maltby, Wood, Vlaev, Taylor, \& Brown, 2012; Sproesser, Klusmann, Schupp, \& Renner, 2015; Stanton, Danoff-Burg, Cameron, Snider, \& Kirk, 1999; see also Dunning, Heath, \& Suls, 2004). For example, Klein (1997) found that participants given both their absolute risk and comparative risk for causing an automobile accident were significantly influenced by their comparative risk in determining if they would 
enroll in a driver safety program. Related results have been found for medical scenarios (Fagerlin, Zikmund-Fisher, \& Ubel, 2007; see also Flugstad \& Windschitl, 2003).

In much of the social comparison research cited above, the comparison standards are manipulated and presented in an intervention, yielding compelling evidence that comparisons can trigger changes in health-related judgments, intentions, and behaviors. Here, we sought to capture people's comparison beliefs as they exist outside of any manipulation. It is possible that measured comparison beliefs are not as predictive as experimental studies suggest, but this can only be determined empirically.

In previous studies that measured both absolute and comparative risk perceptions, findings are somewhat mixed regarding the relative influence of absolute versus comparative risk perceptions on intentions and behaviors. Some work has shown that both types of measures were significantly correlated with intention to change behavior, and in some cases, comparative measures had higher zero-order correlations than absolute measures (e.g., Renner \& Reuter, 2012; Portnoy, Kaufman, Klein, Doyle, \& De Groot, 2014). Others however, have found that only absolute measures were predictive (e.g., Hay et al., 2016; Janssen, van Osch, de Vries, \& Lechner, 2011). Even further, Dillard and colleagues (2011) found that both comparative and absolute measures of cancer risk perceptions were predictive of intentions to change behavior, but only absolute measures remained predictive in regression analyses. In contrast, others have found that comparative measures were predictive of intentions to change behavior above and beyond absolute measures (Klein, 2002; Rose, 2010). In addition to all this, there is the possibility that comparative and absolute risk beliefs interact in predicting behavioral intentions (see Portnoy, Kaufman, Klein, Doyle, \& Groot, 2014). ${ }^{1}$ Needless to say, the evidence about the influence of absolute versus comparative information on intentions to change health behaviors is mixed. 
Notably, social comparisons involving global and local standards might be differentially predictive. Research on the local dominance effect suggests that local comparisonscomparisons to individuals such as friends, family, or classmates - have greater influence on the self than global comparisons, which are comparisons to the average person or a larger group (Alicke, Zell, \& Bloom, 2010; Bruchmann \& Evan, 2013; Buckingham \& Alicke, 2002; Klein, 1997, 2003; Mussweiler \& Rüter, 2003; Zell \& Alicke, 2009, 2010). In typical experiments examining the effect, both the comparison group and feedback to the participant are manipulated to give contradictory local and global feedback (e.g., performing better on a test compared to one's classmates but worse compared to the nation's average, see Zell \& Alicke, 2010). In a health-relevant study, Zell and Alicke (2013) gave manipulated local and global feedback to participants who expressed concern about diabetes. On subsequent self-evaluations of risk perception, participants who received the contradictory global and local feedback were more influenced by local than global feedback, even though participants who received just the global feedback were influenced by it. In a study that measured comparisons rather than manipulated them, Klein (2002) also found evidence consistent with a local dominance effect. Klein (2002) found that comparative risk perceptions about likelihood to gain weight were more predictive of behavioral intentions than absolute risk, and that among different types of comparisons, local comparisons explained the most variance.

\section{The Current Research}

Although perceived importance of change has been previously proposed as a key precursor to motivation to change (Miller \& Johnson, 2008; Rollnick, Mason, \& Butler, 1999), there is a dearth of research on the possible predictors of importance. In the current research, we had two main research questions pertaining to people's perceptions of the importance of changing their health behavior and to their comparative and absolute beliefs about how much 
they already do those behaviors: 1) Are comparison-frequency beliefs predictive of importance of change beyond absolute-frequency beliefs? 2) Are some types of comparison-frequency beliefs (involving expert, global, or local standards) more predictive of importance of change than others? We know of no prior studies examining how these absolute and comparative beliefs predict perceived importance of changing one's behaviors. The most relevant body of research, which we reviewed above, concerns various forms of risk perceptions. As discussed, that work supports mixed findings about how absolute and comparative risk perceptions relate to outcome measures.

In previous research that measured perceived importance of change (e.g., Bertholet et al., 2012; Williams, Horton, Samet, \& Saitz, 2007) it has typically been measured using a single item akin to "How important is it for you to change your behavior?" from 1 (not at all important) to 10 (extremely important). For the current research, we developed an expanded measure of perceived importance of change (described below) meant to assess the perceived importance of increasing healthy behaviors.

In the current project, we conducted three studies with very similar materials and used the same cross-sectional design. Each study also involved the same three heath-behavior domains-exercise, fruit and vegetable consumption, and sleep. We combined the studies (but not domains) for analysis. The outcome variable was always the perceived importance of changing one's behavior. Our participants were simply queried about their comparison beliefs rather than exposed to manipulated comparisons, which allowed us to examine natural variation in comparison beliefs to gauge their typical predictive strengths. Because of the mixed prior evidence reviewed above, we offer no a priori predictions about the directions of the predictiveefficacy differences we investigated. 


\section{Method}

\section{Participants}

Although we established one dataset overall, there were technically three studies, each with its own sample. As we used a correlational research design, we based our sample size for each study on guidelines suggesting that correlations become statistically stable and have reduced estimation error when $N \approx 250$ (Schönbrodt \& Perugini, 2013). The first sample ( $N=242$; 164 female, 77 male, 1 unreported, $\left.M_{a g e}=19.29, S D=1.87\right)$ and the third sample $(N=291 ; 226$ female, 63 male, 2 unreported, $\left.M_{a g e}=18.80, S D=1.28\right)$ consisted of undergraduate students who completed the survey in a laboratory setting and received research requirement credits. The second sample was collected on Amazon MTurk $(N=211 ; 107$ female, 88 male, 16 unreported, $M_{a g e}=36.14, S D=13.23$ ). The combined sample therefore included 744 participants (497 female, 228 male, 19 unreported, $\left.M_{a g e}=23.63, S D=10.32\right)$.

\section{Overview of Design and Procedure}

The three studies shared the same procedures and within-subject design. Each participant completed all measures for each of the three behaviors (exercise, fruit/vegetable consumption, sleep). Participants always answered the importance-of-change items first-six for each of the three behaviors. Next, participants answered items about amount-relevant beliefs-i.e., absolute behavior estimates and direct comparison questions involving global, local, and expert standards. Elaborate counterbalancing and randomization was used (see Online Supplementary Files). Additional items were also included but were secondary, appeared after the items mentioned above, and are not further discussed in the main text. These included absolute estimates that could be used to compute indirect comparative estimates for global, local, and expert standards and a percentile question for each behavior (see Online Supplementary Files for full description).

\section{Measures}


Importance-of-change measures. Our main outcome variable, perceived importance of change, was assessed using 6 items for each of the three behaviors. The 6 items were worded the same for each behavior. The 6 items for sleep were 'I should try to get more sleep overall', 'Getting more sleep should be a priority for me', 'It is important to get more sleep than I currently do', 'It would be a good thing for my health if I got more sleep than I typically do', 'I'm concerned that I don't get enough sleep on average', and 'On a day-to-day basis, I'm aware I should be sleeping more than I do.' For each item, participants responded on a scale from 1 (strongly disagree) to 5 (strongly agree). We aggregated across the items to create a mean importance-of-change composite for each behavior domain.

For each behavior, we conducted an exploratory factor analyses on the six importance-ofchange items. Each of the three analyses revealed a one-factor solution. The single factors explained an average of $73.78 \%$ of the variance in the data. This, in conjunction with high Cronbach's $\alpha$ for the importance-of-change data per behavior (average $\alpha=.94$ ), supports our use of the 6 items in the importance-of-change composites. See the Online Supplementary Files for more information about the factor analyses.

Amount-relevant beliefs. In describing the measures of amount-relevant beliefs below, we use mostly sleep examples. The wording for exercise and fruit/vegetable consumption were analogous to those.

Absolute behavior estimates. A common-rule self-estimate question measured absolute behavior frequency. For sleep, the question was 'How many [hours of sleep] do you get per [night]?' with a drop-down menu from 1 to 15 hours per night. The answers for fruit-andvegetable consumption ranged from 0 to 12 servings per day, and exercise responses included 0 to 16 hours per week. After each common-rule question was a Likert-type question (e.g., 'How much sleep do you tend to get?' $1=$ I sleep very little, $7=$ I sleep a lot'). However, in the 
analyses for this paper, we do not include the Likert-type questions about self-frequencies of the behaviors. $^{2}$

Direct comparison questions. In all three studies, there were three types of direct comparison measures: global, local, and expert. In a minor change between the second and third studies, we altered the wording of the global and local questions to emphasize that the global comparison reflected an aggregate comparison while the local comparison reflected a comparison against a singular person, in line with the review of local versus global comparisons by Zell and Alicke (2010).

Direct global comparison questions (for sleep) asked 'Think about an average person your age and gender. How much sleep do you typically get compared to the average person?' In Study 3, the wording of the direct global question was changed to 'Think about all University of [blinded] students. How much sleep do you typically get compared to University of [blinded] students?'

Direct local comparison questions asked 'Think about your close peers (people you see or hang out with often). How much sleep do you typically get compared to your close peers?' In Study 3, the wording of the direct local question was 'Think about your closest friend. How much sleep do you typically get compared to your closest friend?'

Direct expert questions for all three studies asked 'Think about the amount of sleep that experts recommend. How much sleep do you typically get compared to what experts recommend?' Participants were not provided with the actual expert recommendations and instead were required to rely on their own knowledge (see Online Supplementary Materials for more details regarding assumed vs. actual recommendations).

The three direct comparison questions were answered on scales ranging from -3 (I sleep significantly less than ...) to +3 (I sleep significantly more than ...), which were scored 1-7. 


\section{Analytical Procedure}

All statistical analyses were conducted using Version 25.0 of IBM SPSS statistics software. The three studies were combined into one data set using the Merge Files command in SPSS. Missing data was not imputed and was instead listwise deleted for relevant analyses through SPSS. There was less than $1 \%$ of data missing from the data set (fewer than 2 cases for each measure).

To test our key research questions, a series of Pearson correlations and hierarchical linear regressions were run for each of the three behaviors. The Pearson correlations examined the relationship between importance of change and each of the predictor variables, as well as among the predictor variables themselves. Fisher's r-to-z transformations (calculated from Lee \& Preacher, 2013) were used to compare the strength of the correlations. For each of the hierarchical linear regressions, importance of change was always the outcome variable and the first step always had the absolute behavior estimate for that behavior. The second step was a combination of the direct comparison measures, as informed by our research questions (see the Results section below for more details for each of the individual analyses). Lastly, we ran a series of hierarchical regressions to examine possible interactions between different direct comparison measures.

\section{Results}

The key results were essentially the same across the three studies (i.e., did not interact with study; see Online Supplementary Materials), so here we report analyses for the combined dataset. The Online Supplementary Materials has a variety of additional analyses and results, including analyses testing for the presence of sample-level comparative optimism effects using the direct comparison measures.

Again, the main focus of this research is on the relative predictive power of four amount- 
relevant beliefs: absolute estimates of frequency/amount and comparative estimates against expert, global, and local standards. Table 1 displays correlations involving importance of change and the predictor variables. For each behavior, there was a significant inverse relationship between absolute estimates of behavior and importance-of-change scores. This seems to follow intuitive logic: the more participants reported engaging in a behavior, the less they thought it was important to change that behavior. Similarly, each type of direct comparison estimate was inversely related to importance of change. In fact, the zero-order correlations between each type of direct comparison estimate and importance of change all fell within the range of -.38 to -.63. Also, the three types of direct comparison estimates tended to be intercorrelated, with most of those pairwise comparisons falling between 0.50 and 0.70 . These correlations reveal that among a sample of people who are simply queried at a given moment (and not provided with comparison information), their beliefs about how their healthy behaviors compare to global, local, and expert standards are closely related.

Despite the tight relations among predictor variables, a consistent pattern across behaviors emerged for how they were related to perceived importance of change. Although each type of direct comparison had a negative correlation with perceived importance of change, the strength of their relationship differed. Expert comparisons consistently had the strongest relationship (exercise: -.58; fruits and vegetable consumption: -.51; sleep: -.63), while local comparisons, although significant, had the weakest relationship across behaviors (exercise: -.41; fruits and vegetable consumption: -.38; sleep: -.48). When comparing the strength of the correlations using Fisher's r-to-z transformations (calculated from Lee \& Preacher, 2013), there were significant differences between the expert and local direct comparisons and their relationship with importance of change (exercise: $z=-6.32, p<.001$; fruit and vegetable consumption: $z=-4.32, p<.001$; sleep: $z=-5.49, p<.001$ ). 
Table 1.

Correlations with Importance of Change and Predictors

\begin{tabular}{|c|c|c|c|c|c|c|c|c|}
\hline \multirow[b]{2}{*}{ Behavior } & \multirow[b]{2}{*}{ Measure } & \multirow[b]{2}{*}{$M$} & \multirow[b]{2}{*}{$S D$} & \multirow[b]{2}{*}{ Range } & \multicolumn{4}{|c|}{ Correlations } \\
\hline & & & & & 1 & 2 & 3 & 4 \\
\hline \multirow{5}{*}{$\underline{\text { Exercise }}$} & 1. Importance of Change & 3.86 & 0.99 & $1-5$ & - & & & \\
\hline & 2. Self Common-Rule & 4.22 & 3.24 & $0-16$ & -.50 & - & & \\
\hline & 3. Direct Global Comparisons & 3.83 & 1.59 & $1-7$ & -.51 & .62 & - & \\
\hline & 4. Direct Local Comparisons & 4.12 & 1.55 & $1-7$ & -.41 & .51 & .67 & - \\
\hline & 5. Direct Expert Comparisons & 3.21 & 1.61 & $1-7$ & -.58 & .70 & .76 & .61 \\
\hline \multirow{5}{*}{$\frac{\frac{\text { Fruit and }}{\text { Vegetable }}}{\text { Consumption }}$} & 1. Importance of Change & 3.91 & 0.89 & $1-5$ & - & & & \\
\hline & 2. Self Common-Rule & 2.59 & 1.89 & $0-12$ & -.42 & - & & \\
\hline & 3. Direct Global Comparisons & 4.07 & 1.41 & $1-7$ & -.44 & .55 & - & \\
\hline & 4. Direct Local Comparisons & 4.20 & 1.45 & $1-7$ & -.38 & .47 & .69 & - \\
\hline & 5. Direct Expert Comparisons & 3.02 & 1.40 & $1-7$ & -.51 & .52 & .59 & .55 \\
\hline \multirow{5}{*}{ Sleep } & 1. Importance of Change & 3.67 & 1.18 & $1-5$ & - & & & \\
\hline & 2. Self Common-Rule & 6.81 & 1.35 & $2-12$ & -.61 & - & & \\
\hline & 3. Direct Global Comparisons & 4.09 & 1.36 & $1-7$ & -.53 & .68 & - & \\
\hline & 4. Direct Local Comparisons & 4.12 & 1.35 & $1-7$ & -.49 & .62 & .74 & - \\
\hline & 5. Direct Expert Comparisons & 3.22 & 1.41 & $1-7$ & -.63 & .70 & .64 & .62 \\
\hline
\end{tabular}

Note: All correlations significant at $p<.01$. Direct Global descriptives includes all three studies. 
There were also smaller but significant differences between expert and global comparisons and their relationship with importance of change (exercise: $z=-3.35, p<.001$; fruit and vegetable consumption: $z=-2.56, p=.011$; sleep: $z=-4.01, p<.001$ ), and between global and local comparisons and their relationship with importance of change, with the exception of the behavior of sleep (exercise: $z=-3.92, p<.001$; fruit and vegetable consumption: $z=-2.18, p=.029$; sleep: $z=-1.83, p=.068)$.

\section{Do comparisons add predictive power beyond absolute estimates?}

We will now report a series of hierarchical linear regressions that allow us to answer our two key questions, namely to examine if the different types of comparisons, individually and together, were predictive of importance of change beyond what absolute behavior frequency predicts. Although the intercorrelations among predictors places an upper bound on the ability of each variable to independently contribute to predicting importance-of-change scores in regression analyses, the intercorrelations were not prohibitively high for finding differences (see footnote for discussion of multicollinearity issues). ${ }^{3}$ A series of regressions were run separately for each of the three behaviors. Importance of change was the outcome variable for each of the regressions. The first step of the regression for a given behavior included the common-rule selfestimates of the behavior frequency as the only predictor, and the second step added the three types of direct-comparison estimates as additional predictors. ${ }^{4}$

The results are shown in Table 2. In the first step of the regressions, absolute behavior frequency (i.e., self common rule) was a significant predictor of participants' perceived importance of changing the given behavior; this was true for exercise $(\beta=-.505, t(739)=-15.898$, $p<.001)$, fruit and vegetable consumption $(\beta=-.423, t(742)=-12.698, p<.001)$, and sleep $(\beta=-.607$, $t(741)=-20.815, p<.001)$. Despite the predictive power of the absolute estimates of behavior 
frequency, there was still plenty of variance left in importance-of-change scores to be explained (adjusted $R^{2}=0.25,0.18$, and 0.37 , respectively).

For all three behaviors, the second step of the model offered a significant improvement over the first for predicting importance of change (Exercise: $F(4,736)=105.63, R_{\text {change }}^{2}=.110$, $p<.001$; Fruit and vegetable consumption: $F(4,737)=81.63, R_{\text {change }}^{2}=.128, p<.001$; Sleep: $\left.F(4,738)=153.58, R_{\text {change }}=.085, p<.001\right)$. In other words, the combination of the three comparisons predicted participants' beliefs about how important it is to change their behaviors beyond what their absolute behavior frequency predicted. Despite this, the absolute estimates maintained significant predictive validity in the final models, suggesting that while the comparisons are adding additional predictive value, they are not displacing absolute behavior frequency.

Another notable feature of the final models is that, of the three direct comparisons, the expert comparisons remain a relatively strong, significant predictor in all three behavior domains (see Table 2). Global comparisons remained significant predictors in two of the three behaviors, and just shy of significance in the third behavior, but with relatively less strength than expert comparisons. Local comparisons were not significant predictors in any of the three behavior domains (all $p \mathrm{~s}>.40$ ). It is certainly noteworthy that there is consistency across the three domains with the apparent superiority of expert comparisons in predicting importance-of-change beliefs, and there is consistency in the null findings for local comparisons. However, this does not necessarily mean that local comparisons are unimportant, nor that they would not add predictive power when added to a model without the others. This type of question is addressed in the following analyses, for which we examined, separately for each type of direct comparison type and behavior domain, whether a given comparison type - absent the other comparisons — would add predictive power beyond what is achieved by self-estimates of behavior frequency. 
Table 2.

Hierarchical Linear Regressions with Self-Estimates and Direct Comparisons Predicting Importance of

Change

\begin{tabular}{|c|c|c|c|c|c|c|c|c|c|c|c|}
\hline \multirow[b]{2}{*}{ Behavior } & \multirow[b]{2}{*}{ Step and Variable } & \multirow[b]{2}{*}{$b$} & \multicolumn{2}{|c|}{$95 \%$ CI for $b$} & \multirow[b]{2}{*}{$\beta$} & \multirow[b]{2}{*}{$t$} & \multirow[b]{2}{*}{$p$} & \multicolumn{4}{|c|}{ Model Results Per Step } \\
\hline & & & Lower-bound & $\begin{array}{l}\text { Upper- } \\
\text { bound }\end{array}$ & & & & $d f$ & $R^{2}$ & $\Delta R^{2}$ & $\begin{array}{l}\text { Sig. } \\
\Delta F\end{array}$ \\
\hline \multirow{6}{*}{$\underline{\text { Exercise }}$} & Step 1 & & & & & & & & & & \\
\hline & $\begin{array}{l}\text { Self Common-Rule } \\
\text { Step } 2\end{array}$ & -.154 & -.173 & -.135 & -.505 & -15.90 & $<.001$ & 739 & .254 & .255 & $<.001$ \\
\hline & Self Common-Rule & -.050 & -.076 & -.025 & -.165 & -3.92 & $<.001$ & 736 & .361 & .110 & $<.001$ \\
\hline & Local Comparison & -.019 & -.070 & -.031 & -.030 & -0.75 & .454 & & & & \\
\hline & Global Comparison & -.073 & -.135 & -.012 & -.117 & -2.35 & .019 & & & & \\
\hline & Expert Comparison & -.220 & -.282 & -.158 & -.358 & -6.98 & $<.001$ & & & & \\
\hline \multirow{7}{*}{$\frac{\underline{\text { Fruit and }}}{\text { Vegetable }}$} & Step 1 & & & & & & & & & & \\
\hline & Self Common-Rule & -.200 & -.231 & -.169 & -.423 & -12.70 & $<.001$ & 740 & .178 & .179 & $<.001$ \\
\hline & Step 2 & & & & & & & & & & \\
\hline & Self Common-Rule & -.079 & -.115 & -.044 & -.168 & -4.36 & $<.001$ & 737 & .303 & .128 & $<.001$ \\
\hline & Local Comparison & -.018 & -.071 & .036 & -.028 & -0.65 & .517 & & & & \\
\hline & Global Comparison & -.083 & -.141 & -.025 & -.131 & -2.81 & .005 & & & & \\
\hline & Expert Comparison & -.210 & -.261 & -.160 & -.331 & -8.16 & $<.001$ & & & & \\
\hline \multirow{6}{*}{ Sleep } & Step 1 & & & & & & & & & & \\
\hline & $\begin{array}{l}\text { Self Common-Rule } \\
\text { Step } 2\end{array}$ & -.526 & -.576 & -.477 & -.607 & -20.82 & $<.001$ & 741 & .368 & .369 & $<.001$ \\
\hline & Self Common-Rule & -.247 & -.319 & -.175 & -.285 & -6.76 & $<.001$ & 738 & .451 & .085 & $<.001$ \\
\hline & Local Comparison & -.017 & -.090 & .055 & -.020 & -0.47 & .639 & & & & \\
\hline & Global Comparison & -.076 & -.152 & .000 & -.088 & -1.96 & .051 & & & & \\
\hline & Expert Comparison & -.298 & -.365 & -.232 & -.360 & -8.83 & $<.001$ & & & & \\
\hline
\end{tabular}

Note: $R^{2}$ represents adjusted $R^{2}$. 


\section{Which specific comparisons add predictive power beyond absolute estimates?}

Table 3 shows results from hierarchical linear regressions for each behavior with selfestimates of behavior frequency in the first step and the expert comparison in the second step. For each behavior, the second models were significantly more predictive of importance of change than the first models, with expert comparisons predicting between 8.1 and $11.6 \%$ of the variance above and beyond absolute frequency. For illustration, if we reverse the order of the steps in the model, then the self-estimates of behavior frequency only predict between 1.8 and $5.7 \%$ of the variance above expert comparisons.

Table 4 shows results for the same analyses, except that global comparisons replaced the expert comparisons. Recall that the direct global comparison question for Studies 1 and 2 differed from the question asked in Study 3. Because of this wording difference, two series of regressions were run for each behavior: one using the combined data from Studies 1 and 2 and one using the data from Study 3. In both of these versions, the second models (i.e., those with both absolute frequency and global comparisons) were significantly more useful in predicting importance of changing behavior than the first models. This was true for all three behavior domains. Global comparisons predicted between 3.0 and $8.4 \%$ of the variance above and beyond absolute frequency. If we reverse the order of the steps in the model, then absolute frequency predicts between 3.7 and $13.1 \%$ more variance than the global comparisons.

Table 5 shows results for the same analyses involving local comparisons. With the combined samples from the first two studies, the second model predicted significantly more variance in importance of changing all 3 behaviors. The same was true for two of the three behaviors from Study 3 (sleep was the exception; $p=.094$ ). 
Table 3.

Hierarchical Linear Regressions with Self-Estimates and Expert Comparisons Predicting Importance of Change

\begin{tabular}{|c|c|c|c|c|c|c|c|c|c|c|c|}
\hline \multirow[b]{2}{*}{ Behavior } & \multirow[b]{2}{*}{ Step and Variable } & \multirow[b]{2}{*}{$b$} & \multicolumn{2}{|c|}{$95 \% \mathrm{CI}$ for $b$} & \multirow[b]{2}{*}{$\beta$} & \multirow[b]{2}{*}{$t$} & \multirow[b]{2}{*}{$p$} & \multicolumn{4}{|c|}{ Model Results Per Step } \\
\hline & & & $\begin{array}{l}\text { Lower- } \\
\text { bound }\end{array}$ & $\begin{array}{l}\text { Upper- } \\
\text { bound }\end{array}$ & & & & $d f$ & $R^{2}$ & $\Delta R^{2}$ & Sig. $\Delta F$ \\
\hline \multirow{5}{*}{ Exercise } & Step 1 & & & & & & & & & & \\
\hline & Self Common-Rule & -.154 & -.173 & -.135 & -.503 & -15.85 & $<.001$ & 741 & .252 & .253 & $<.001$ \\
\hline & Step 2 & & & & & & & & & & \\
\hline & Self Common-Rule & -.057 & -.082 & -.032 & -.188 & -4.54 & $<.001$ & 740 & .355 & .103 & $<.001$ \\
\hline & Expert Comparison & -.276 & -.326 & -.226 & -.450 & -10.89 & $<.001$ & & & & \\
\hline \multirow{5}{*}{$\underline{\frac{\text { Fruit and }}{\text { Vegetable }}}$} & Step 1 & & & & & & & & & & \\
\hline & Self Common-Rule & -.200 & -.231 & -.169 & -.423 & -12.70 & $<.001$ & 741 & .178 & .179 & $<.001$ \\
\hline & Step 2 & & & & & & & & & & \\
\hline & Self Common-Rule & -.104 & -.137 & -.070 & -.219 & -6.07 & $<.001$ & 740 & .293 & .116 & $<.001$ \\
\hline & Expert Comparison & -.252 & -.297 & -.207 & -.397 & -11.01 & $<.001$ & & & & \\
\hline \multirow{5}{*}{ Sleep } & Step 1 & & & & & & & & & & \\
\hline & Self Common-Rule & -.526 & -.576 & -.477 & -.607 & -20.82 & $<.001$ & 741 & .368 & .369 & $<.001$ \\
\hline & Step 2 & & & & & & & & & & \\
\hline & Self Common-Rule & -.289 & -.353 & -.224 & -.333 & -8.77 & $<.001$ & 740 & .448 & .081 & $<.001$ \\
\hline & Expert Comparison & -.328 & -.389 & -.266 & -.395 & -10.40 & $<.001$ & & & & \\
\hline
\end{tabular}

Note: $R^{2}$ represents adjusted $R^{2}$. 
Table 4.

Hierarchical Linear Regressions with Self-Estimates and Global Comparisons Predicting Importance of Change

\begin{tabular}{|c|c|c|c|c|c|c|c|c|c|c|c|}
\hline \multirow{2}{*}{$\begin{array}{c}\text { Behavior and } \\
\text { Study }\end{array}$} & \multirow[b]{2}{*}{ Step and Variable } & \multirow[b]{2}{*}{$b$} & \multicolumn{2}{|c|}{$95 \%$ CI for $b$} & \multirow[b]{2}{*}{$\beta$} & \multirow[b]{2}{*}{$t$} & \multirow[b]{2}{*}{$p$} & \multicolumn{4}{|c|}{ Model Results Per Step } \\
\hline & & & $\begin{array}{l}\text { Lower- } \\
\text { bound }\end{array}$ & $\begin{array}{l}\text { Upper- } \\
\text { bound }\end{array}$ & & & & $d f$ & $R^{2}$ & $\Delta R^{2}$ & Sig. $\Delta F$ \\
\hline Exercise & Step 1 & & & & & & & & & & \\
\hline \multirow{4}{*}{ Study $1 \& 2$} & Self Common-Rule & -.152 & -.176 & -.127 & -.499 & -12.23 & $<.001$ & 450 & .248 & .249 & $<.001$ \\
\hline & Step 2 & & & & & & & & & & \\
\hline & Self Common-Rule & -.089 & -.119 & -.060 & -.294 & -5.92 & $<.001$ & 449 & .314 & .068 & $<.001$ \\
\hline & Global Comparison & -.201 & -.260 & -.142 & -.332 & -6.67 & $<.001$ & & & & \\
\hline \multirow{5}{*}{ Study 3} & Step 1 & & & & & & & & & & \\
\hline & Self Common-Rule & -.156 & -.188 & -.125 & -.498 & -9.75 & $<.001$ & 289 & .245 & .248 & $<.001$ \\
\hline & Step 2 & & & & & & & & & & \\
\hline & Self Common-Rule & -.087 & -.127 & -.047 & -.277 & -4.33 & $<.001$ & 288 & .310 & .067 & $<.001$ \\
\hline & Global Comparison & -.222 & -.304 & -.140 & -.340 & -5.32 & $<.001$ & & & & \\
\hline $\begin{array}{l}\text { Fruit and } \\
\text { Vegetable }\end{array}$ & Step 1 & & & & & & & & & & \\
\hline \multirow{4}{*}{ Study $1 \& 2$} & Self Common-Rule & -.209 & -.249 & -.168 & -.430 & -10.11 & $<.001$ & 450 & .183 & .185 & $<.001$ \\
\hline & Step 2 & & & & & & & & & & \\
\hline & Self Common-Rule & -.140 & -.188 & -.092 & -.289 & -5.77 & $<.001$ & 449 & .226 & .044 & $<.001$ \\
\hline & Global Comparison & -.157 & -.218 & -.096 & -.253 & -5.06 & $<.001$ & & & & \\
\hline \multirow{5}{*}{ Study 3} & Step 1 & & & & & & & & & & \\
\hline & Self Common-Rule & -.187 & -.235 & -.138 & -.408 & -7.59 & $<.001$ & 289 & .163 & .166 & $<.001$ \\
\hline & Step 2 & & & & & & & & & & \\
\hline & Self Common-Rule & -.104 & -.158 & -.050 & -.227 & -3.78 & $<.001$ & 288 & .245 & .084 & $<.001$ \\
\hline & Global Comparison & -.224 & -.302 & -.147 & -.341 & -5.67 & $<.001$ & & & & \\
\hline Sleep & Step 1 & & & & & & & & & & \\
\hline$\underline{\text { Study } 1 \& 2}$ & $\begin{array}{l}\text { Self Common-Rule } \\
\text { Step } 2\end{array}$ & -.531 & -.597 & -.466 & -.602 & -16.03 & $<.001$ & 451 & .362 & .363 & $<.001$ \\
\hline
\end{tabular}


COMPARISONS AND CHANGE

\begin{tabular}{|c|c|c|c|c|c|c|c|c|c|c|c|}
\hline & $\begin{array}{l}\text { Self Common-Rule } \\
\text { Global Comparison }\end{array}$ & $\begin{array}{l}-.381 \\
-.212\end{array}$ & $\begin{array}{l}-.471 \\
-.302\end{array}$ & $\begin{array}{l}-.291 \\
-.123\end{array}$ & $\begin{array}{l}-.432 \\
-.242\end{array}$ & $\begin{array}{l}-8.35 \\
-4.68\end{array}$ & $\begin{array}{l}<.001 \\
<.001\end{array}$ & 450 & .390 & .030 & $<.001$ \\
\hline Study 3 & $\begin{array}{l}\text { Step } 1 \\
\quad \text { Self Common-Rule } \\
\text { Step } 2\end{array}$ & -.534 & -.610 & -.459 & -.634 & -13.96 & $<.001$ & 289 & .401 & .403 & $<.001$ \\
\hline & $\begin{array}{l}\text { Self Common-Rule } \\
\text { Global Comparison }\end{array}$ & $\begin{array}{l}-.402 \\
-.208\end{array}$ & $\begin{array}{l}-.499 \\
-.307\end{array}$ & $\begin{array}{l}-.305 \\
-.110\end{array}$ & $\begin{array}{c}.477 \\
-.242\end{array}$ & $\begin{array}{l}-8.19 \\
-4.15\end{array}$ & $\begin{array}{l}<.001 \\
<.001\end{array}$ & 288 & .432 & .034 & $<.001$ \\
\hline
\end{tabular}

Note: $R^{2}$ represents adjusted $R^{2}$.

22 
Table 5.

Hierarchical Linear Regressions with Self-Estimates and Local Comparisons Predicting Importance of Change

\begin{tabular}{|c|c|c|c|c|c|c|c|c|c|c|c|}
\hline \multirow{2}{*}{$\begin{array}{c}\text { Behavior and } \\
\text { Study }\end{array}$} & \multirow{2}{*}{ Step and Variable } & \multirow[b]{2}{*}{$b$} & \multicolumn{2}{|c|}{$95 \% \mathrm{CI}$ for $b$} & \multirow[b]{2}{*}{$\beta$} & \multirow[b]{2}{*}{$t$} & \multirow[b]{2}{*}{$p$} & \multicolumn{4}{|c|}{ Model Results Per Step } \\
\hline & & & Lower-bound & Upper-bound & & & & $d f$ & $R^{2}$ & $\Delta R^{2}$ & Sig. $\Delta F$ \\
\hline \multirow{5}{*}{$\begin{array}{l}\text { Exercise } \\
\qquad \text { Study } 1 \& 2\end{array}$} & Step 1 & & & & & & & & & & \\
\hline & Self Common-Rule & -.154 & -.173 & -.135 & -.504 & -15.87 & $<.001$ & 741 & .253 & .254 & $<.001$ \\
\hline & Step 2 & & & & & & & & & & \\
\hline & Self Common-Rule & -.121 & -.143 & -.099 & -.396 & -10.98 & $<.001$ & 740 & .284 & .033 & $<.001$ \\
\hline & Local Comparison & -.134 & -.179 & -.089 & -.210 & -5.83 & $<.001$ & & & & \\
\hline \multirow{5}{*}{$\underline{\text { Study } 3}$} & Step 1 & & & & & & & & & & \\
\hline & Self Common-Rule & -.157 & -.188 & -.125 & -.498 & -9.76 & $<.001$ & 288 & .246 & .248 & $<.001$ \\
\hline & Step 2 & & & & & & & & & & \\
\hline & Self Common-Rule & -.146 & -.180 & -.112 & -.464 & -8.47 & $<.001$ & 287 & .251 & .007 & .094 \\
\hline & Local Comparison & -.052 & -.114 & .009 & -.092 & -1.68 & .094 & & & & \\
\hline \multirow{5}{*}{$\begin{array}{l}\text { Fruit and } \\
\text { Vegetable } \\
\qquad \text { Study } 1 \& 2\end{array}$} & Step 1 & & & & & & & & & & \\
\hline & Self Common-Rule & -.200 & -.231 & -.169 & -.423 & -12.71 & $<.001$ & 742 & .178 & .179 & $<.001$ \\
\hline & Step 2 & & & & & & & & & & \\
\hline & Self Common-Rule & -.149 & -.183 & -.115 & -.315 & -8.59 & $<.001$ & 741 & .219 & .042 & $<.001$ \\
\hline & Local Comparison & -.143 & -.187 & -.098 & -.232 & -6.33 & $<.001$ & & & & \\
\hline \multirow{5}{*}{$\underline{\text { Study } 3}$} & Step 1 & & & & & & & & & & \\
\hline & Self Common-Rule & -.187 & -.235 & -.138 & -.408 & -7.59 & $<.001$ & 289 & .163 & .166 & $<.001$ \\
\hline & Step 2 & & & & & & & & & & \\
\hline & Self Common-Rule & -.137 & -.188 & -.087 & -.300 & -5.36 & $<.001$ & 288 & .227 & .067 & $<.001$ \\
\hline & Local Comparison & -.159 & -.222 & -.096 & -.280 & -5.01 & $<.001$ & & & & \\
\hline \multirow{4}{*}{$\begin{array}{l}\text { Sleep } \\
\qquad \underline{\text { Study } 1 \& 2}\end{array}$} & Step 1 & & & & & & & & & & \\
\hline & Self Common-Rule & -.529 & -.578 & -.479 & -.608 & -20.89 & $<.001$ & 742 & .369 & .370 & $<.001$ \\
\hline & Step 2 & & & & & & & & & & \\
\hline & Self Common-Rule & -.432 & -.494 & -.370 & -.497 & -13.60 & $<.001$ & 741 & .388 & .020 & $<.001$ \\
\hline
\end{tabular}


COMPARISONS AND CHANGE

\begin{tabular}{|c|c|c|c|c|c|c|c|c|c|c|c|}
\hline & Local Comparison & -.157 & -.219 & -.094 & -.179 & -4.90 & $<.001$ & & & & \\
\hline \multirow[t]{2}{*}{ Study 3} & $\begin{array}{l}\text { Step } 1 \\
\text { Self Common-Rule } \\
\text { Step } 2\end{array}$ & -.538 & -.613 & -.464 & -.641 & -14.19 & $<.001$ & 288 & .409 & .411 & $<.001$ \\
\hline & $\begin{array}{l}\text { Self Common-Rule } \\
\text { Local Comparison }\end{array}$ & $\begin{array}{l}-.476 \\
-.102\end{array}$ & $\begin{array}{l}-.563 \\
-.177\end{array}$ & $\begin{array}{l}-.390 \\
-.027\end{array}$ & $\begin{array}{l}-.567 \\
-.141\end{array}$ & $\begin{array}{l}-10.80 \\
-2.69\end{array}$ & $\begin{array}{c}<.001 \\
.008\end{array}$ & 287 & .422 & .014 & .008 \\
\hline
\end{tabular}

Note: $R^{2}$ represents adjusted $R^{2}$.

24 
Overall, the analyses depicted in Tables 3-5 show that the addition of any of the direct comparison estimates to a model that already includes absolute estimates will still add power for predicting importance-of-change beliefs. Notably, however, the additional predictive power appears to be greatest in the case of expert comparisons and smallest in the case of local comparisons. Mixed findings make it difficult to determine if the specific wording used to refer to the local standards makes much of a difference in the pattern of findings.

Global versus local comparisons. Given that research on the local dominance effect typically pits the impact of global comparison information against local comparison information (e.g., Zell \& Alicke, 2009, 2010), we examined their relative influence in regressions. With data from Studies 1 and 2, a two-step hierarchical linear regression was run, with absolute estimates in the first step, and global and local comparisons in the second step (see Table 6). Across the three behaviors, there was a consistent pattern where the second model significantly predicted more variance than the first model (average $R_{\text {change }}^{2}=.052, p \mathrm{~s}<.001$ ). When taking a closer look at the individual coefficients in each model however, local comparisons were just shy of significance, $(p s=.058, .062$, and .067$)$, suggesting that the global comparisons were explaining significantly more variance. When running the same regression models with the third study, global comparisons were significant in each of the final models $\left(p_{\mathbf{s}}<.001\right)$ but local comparisons maintained significance only in the behavior of fruit and vegetable consumption $(p=.002$; all other $p \mathrm{~s}>.05)$. This demonstrates that among these three health behaviors, local comparisons did not seem to maintain the same local dominance effect over global comparisons when predicting participants' importance-of-change beliefs. 
Table 6.

Hierarchical Linear Regressions with Self-Estimates, Global Comparisons, and Local Comparisons Predicting Importance of Change

\begin{tabular}{|c|c|c|c|c|c|c|c|c|c|c|c|}
\hline \multirow[b]{2}{*}{ Behavior } & \multirow[b]{2}{*}{ Step and Variable } & \multirow[b]{2}{*}{$b$} & \multicolumn{2}{|c|}{$95 \%$ CI for $b$} & \multirow[b]{2}{*}{$\beta$} & \multirow[b]{2}{*}{$t$} & \multirow[b]{2}{*}{$p$} & \multicolumn{4}{|c|}{ Model Results Per Step } \\
\hline & & & Lower-bound & $\begin{array}{l}\text { Upper- } \\
\text { bound }\end{array}$ & & & & $d f$ & $R^{2}$ & $\Delta R^{2}$ & Sig. $\Delta F$ \\
\hline \multirow{5}{*}{$\underline{\text { Exercise }}$} & Step 1 & & & & & & & & & & \\
\hline & $\begin{array}{l}\text { Self Common-Rule } \\
\text { Step } 2\end{array}$ & -.153 & -.177 & -.128 & -.502 & -12.29 & $<.001$ & 449 & .250 & .252 & $<.001$ \\
\hline & Self Common-Rule & -.084 & -.115 & -.054 & -.277 & -5.48 & $<.001$ & 447 & .320 & .073 & $<.001$ \\
\hline & Global Comparison & -.164 & -.234 & -.094 & -.271 & -4.60 & $<.001$ & & & & \\
\hline & Local Comparison & -.064 & -.130 & .002 & -.105 & -1.90 & .058 & & & & \\
\hline \multirow{5}{*}{$\frac{\underline{\text { Fruit and }}}{\text { Vegetable }}$} & Step 1 & & & & & & & & & & \\
\hline & $\begin{array}{l}\text { Self Common-Rule } \\
\text { Sten } 2\end{array}$ & -.209 & -.249 & -.168 & -.430 & -10.11 & $<.001$ & 450 & .183 & .185 & $<.001$ \\
\hline & Self Common-Rule & -.133 & -.181 & -.085 & -.275 & -5.46 & $<001$ & 448 & 230 & 050 & $<001$ \\
\hline & Global Comparison & -.115 & -.190 & -.039 & -.185 & -3.00 & .003 & & & & \\
\hline & Local Comparison & -.065 & -.133 & .003 & -.109 & -1.87 & .062 & & & & \\
\hline \multirow{6}{*}{$\underline{\text { Sleep }}$} & Step 1 & & & & & & & & & & \\
\hline & Self Common-Rule & -.531 & -.597 & -.466 & -.602 & -16.03 & $<.001$ & 451 & .362 & .363 & $<.001$ \\
\hline & Step 2 & & & & & & & & & & \\
\hline & Self Common-Rule & -.364 & -.455 & -.272 & -.412 & -7.82 & $<.001$ & 449 & .393 & .034 & $<.001$ \\
\hline & Global Comparison & -.148 & -.261 & -.036 & -.169 & -2.60 & .010 & & & & \\
\hline & Local Comparison & -.099 & -.205 & .007 & -.111 & -1.84 & .067 & & & & \\
\hline
\end{tabular}

Note: Data represented in the table is from Study 1 and 2. $R^{2}$ represents adjusted $R^{2}$. 
Interactions between absolute estimates and comparisons. As stated earlier, it is also possible that comparisons may be differentially predictive of importance-of-change beliefs depending on people's absolute frequency of behavior. To examine this possibility, a three-step hierarchical regression was run, with absolute estimates in the first step, global or local comparisons in the second step, and the interaction term in the third step.

In examining the interaction between global comparisons and absolute estimates, the third model with the interaction term significantly predicted more variance than the second model for the behaviors of exercise and sleep (average $R^{2}$ change $=.019, p \mathrm{~s}<.001$ ), but not for fruit and vegetable consumption $(p>.20)$. For exercise and sleep, there was a consistent pattern — the effect for global comparisons was a bit larger among people with higher absolute estimates than among people with lower absolute estimates. With local comparisons, the third model was only significant for sleep $\left(R_{\text {change }}^{2}=.014, p<.001\right)$, and the pattern exactly matched that of the global comparisons. Given that the interaction effects were inconsistent and of a very small magnitude even when significant, we do not find them consequential for interpreting our other results. ${ }^{5}$

\section{Discussion}

We examined how four amount-relevant beliefs (about absolute behavior frequency and global, local, and expert standards) differentially predicted people's assessments of how important it is to change their health behaviors. Specifically, we had two key research questions: 1) Are comparison-frequency beliefs predictive of importance of change beyond absolutefrequency beliefs? 2) Are some types of comparison-frequency beliefs more predictive of importance of change than others? Past research in which comparisons were staged and manipulated as part of research interventions have provided evidence that comparisons can have powerful influences on a variety of responses (e.g., concerns about health risk, behavioral intentions, and heath-relevant behaviors; Gerber, Wheeler, \& Suls, 2018: Zell \& Alicke, 2010, 
2013). A key feature of the present work is that we measured three different comparison beliefs outside of the context of any staged comparison interventions. This is important because within the variety of everyday life, the salience of specific comparison standards are bound to ebb and flow, yet some might be chronically more influential than others. Our approach allowed us to gauge the relative predictive influences of comparison beliefs as they would generally occur. Of course, with a cross-sectional design in which comparison information was not experimentally manipulated, we are limited in drawing firm causal conclusions from our data alone.

The results were consistent across the three types of behaviors, suggesting that those results reflect rather general tendencies. Participants' responses regarding direct comparisons were strongly related to importance-of-change assessments, and they predicted those assessments beyond what is predictable from estimates of absolute behavior frequency. This suggests that people's assessments of whether they should be doing more of a given health behavior are, at some level, sensitive to whether they think most people or their peers do more than they do, and/or experts recommend more than what they do. Notably, these comparisons don't supersede the influence of absolute behavior frequency. When predicting importance-of-change beliefs, the absolute level of behavior frequency was still predictive, even after all three comparisons were already considered.

Although our results support the idea that comparisons matter, separating out the relative influences of the specific comparisons is challenging. The estimates for the three types of comparisons were interrelated, suggesting that within a sample, the participants who believe that the expert-recommended frequency of a behavior is higher than their own current frequency would also tend to believe that other people and peers are doing more of the behavior. Nevertheless, the results for whether expert, global, and local comparisons were most influential when considered together in regression analyses were consistent across the three behaviors. 
Namely, expert comparisons were most influential and local comparisons were the least influential.

The relatively small size of the influence of local comparisons was surprising, especially given previous findings on the local dominance effect (Buckingham \& Alicke, 2002; Zell \& Alicke, 2010, 2013). The lack of a local dominance effect in our study may be important for understanding how people naturally engage in social comparative processes. When a person thinks about how often they do a health behavior, comparing to an individual local target (e.g., a close friend) may not be as informative as comparing to the average or median amount from larger samples of people. Klein (2002) finds that comparing to a close individual about health risks is not as predictive of behavior intentions as comparing to an 'average other.' This pattern is further supported by two studies (Locke, 2007, Studies 2 and 3) examining people's reports of their naturally-occurring social comparisons, in which comparisons with an average group of people were more influential on overall mood than were comparisons with an individual. The lack of the local dominance effect in these previous studies does not suggest that people do not compare with individual others. Instead, it may mean that comparisons with a specified type of local comparison (e.g., 'friends') do not have special priority and are instead one of many influential comparisons. If people are influenced by every local comparison that they encounter, then the net effect of this may be largely captured when people are asked how they compare to most people or even the 'average person' (c.f., Maltby et al., 2012).

Although our findings suggest that global comparisons had utility for predicting importance of change, some readers might wonder why it did not have even more influence above and beyond absolute frequency, given prior findings (e.g., Klein, 1997, 2002; Rose, 2010). One reason may be due to our focus on the behavior frequency/amount as opposed to previous work's focus on risk perception. Behavior frequency/amount can be represented and measured 
concretely ('I sleep 7 hours per night'). However, representations about levels of risk are typically less concrete (35\% chance of being diagnosed with cancer). Comparative beliefs tend to be influential when there is no objective standard available (Festinger, 1954). While a risk estimate like 'a 35\% chance of being diagnosed with cancer' can still be considered absolute and somewhat concrete for numerically-literate individuals, it may be still ambiguous enough for most people, meaning that comparative information becomes quite useful for knowing how to react (Harris, Sparks, \& Raats, 2002; Weinstein, 1999). In contrast, the concreteness of a behavior estimate like 'I sleep 7 hours' or 'I eat about 4 servings' might make social comparisons less likely to be actively considered.

Still, some comparisons are presumably needed in order for a person to know how to evaluate '7 hours of sleep' or ' 4 servings.' For these sorts of health behaviors, most people have heard something about what experts recommend (e.g., they recommend 8 hours of sleep). A clear expert standard may displace the influence of both global and local comparisons, assuming people find the expert recommendation to be well founded and applicable. When perceptions of risk are involved, there are rarely expert standards for amount of acceptable risk, so using social standards might be more likely. Future research could investigate if the concreteness of known expert recommendations alters the extent to which social-comparative beliefs drive importance of change and related outcomes.

Our research is not without its limitations. One limitation is our use of a cross-sectional design. It would be ideal to examine naturally-occurring comparisons and their influence on actual behavior change using a longitudinal design. Although we cannot make direct causal claims about the influence of social and expert comparisons on perceived importance of change, our design and large sample size allowed us to understand how various types of comparison beliefs intersect in relation to perceived importance of change. Our conclusions are also made in 
light of previous research using manipulated comparisons to reveal causal impacts that comparisons can have on concerns about health risks, behavioral intentions, and heath-relevant behaviors (Mahler, 2018; Rimal \& Real, 2005; Sheeran et al., 2016; Zell \& Alicke, 2013).

An additional limitation is that we relied on self-estimates of absolute behavior frequency instead of recording sleep hours, food consumption, and exercise through direct observation. However, perceptions of behavior frequency are important to examine in this type of research. Presumably, those perceptions, rather than objectively measured values, are what a person evaluates in comparisons to their beliefs about social and expert standards when thinking about whether a change of behavior is needed.

Finally, it is important to note that importance-of-change beliefs are not the same as intentions to change and will not always lead to actual behavior change. As discussed earlier, several theoretical perspectives are consistent with idea that importance-of-change beliefs can be precursors of intentions to change (e.g., Ajzen, 1991; Albarracín et al., 2001; DiClemente \& Velasquez, 2002; Fishbein \& Ajzen, 2010; French et al., 2013; Miller \& Rollnick, 2009; Prochaska et al., 2015). However, these perspectives also posit additional variables that influence intentions and behavior, and these can moderate or mitigate the influence of importance-ofchange beliefs on intentions or behavior. For example, despite our results showing that relatively optimistic social-comparative assessments of one's health behavior predict that people would view change as less important, it is still possible that these relatively optimistic socialcomparative assessments can be positively related to intentions to continue to be healthy in the future (see Sproesser et al., 2015).

\section{Conclusion}

This work focused on amount-related beliefs as they pertain to health behaviors. We examined the relationships among those beliefs as they typically exist in a sample—i.e., absent 
any staged intervention or other manipulation that people might encounter in an experimental study. The findings were remarkably consistent across three important health domains, suggesting that those findings reflect rather general tendencies. People's beliefs about social and expert comparisons were predictive of their assessments of the importance of changing their behavior, and this relationship remained robust even after accounting for absolute behavior frequency. Although comparative beliefs were not highly differentiated in how they order people within a sample, there was enough differentiation to detect two important, additional findings: 1) expert comparisons were most predictive of importance-of-change beliefs, and 2) there was no support for a local dominance effect. The findings highlight the need for more research on how comparison-standard interventions, in which a social or expert comparison is presented for a limited time, play out after the immediate salience of the intervention subsides.

Disclosure statement: The authors have no conflicts of interest to disclose. 


\section{Footnotes}

${ }^{1}$ We thank an anonymous reviewer for suggesting we look further into the possibility of interactions between the predictors. These might occur for different reasons. For example, people whose absolute behavior is extremely low might start to ignore their absolute levels and start emphasizing how they think they compare to peers. Or, a contrary idea is that being at an extreme might create essentially a ceiling at which everyone knows it is important to change their behavior, and peer comparisons do not add or subtract from that belief.

${ }^{2}$ As revealed in a separate project, responses on those Likert-type self-frequency measures are shaped by direct comparisons (citation blinded). Therefore, including them as predictors in our models would obscure the role of the three direct comparisons in predicting importance of change.

3 The correlations could raise concerns about multicollinearity for regression analyses reported later in the results section. It is worth noting that multicollinearity was only a problem when running the hierarchical regression with three comparisons, and that the variance inflation factors were all under the conservative cutoff of 3 (Garson 2012; Tabachnik \& Fidell, 2007). In addition, the significant $F$-tests also produced significant $t$-tests of the coefficients (in the same direction), which indicates that the multicollinearity issue is not severe (Garson, 2012). The hierarchical regression suggested that the expert comparisons held the most predictive value (above absolute frequency estimates) and local comparisons the least predictive. This pattern is also present when looking at the reported individual hierarchical regressions that had no multicollinearity issues. While the significant correlations between comparisons suggests that these constructs are overlapping, but not redundant with each other, the significant overlap may also be due to the similar question formats (citation blinded). 
4 For these regressions, we included the data from all three studies - ignoring the fact that there were slight differences in the wordings of the global comparison measure in Studies 1 and 2 versus Study 3. In other words, when we put the direct global comparison in the second step of the hierarchical regression, it included the data from those who compared against 'the average person' (Studies 1 and 2) and those who compared against 'average University of [blinded] students' (Study 3). We report the influence of wording differences a bit later, in the section where we examine the influence of global comparisons by themselves. As both versions of the local questions were included in the third study, we use data from all three studies from the local question asking about "close peers" in this series of hierarchical regressions.

${ }^{5}$ Similar to the other interaction analyses, we can also examine possible interactions between expert comparisons and global comparisons in a series of hierarchical regressions that had absolute estimates in the first step, global and expert comparisons in the second step, and the global $\mathrm{x}$ expert interaction term in the third step. The third model with the interaction term significantly predicted more variance than the second model for the behaviors of exercise and sleep (average $\left.R_{\text {change }}^{2}=.014, p \mathrm{~s}<.001\right)$, but not for fruit and vegetable consumption $(p>.50)$. The interaction pattern was consistent across both behaviors. Among people who reported lower expert comparisons, there was no difference in their importance of change ratings based on their global comparison rating, but among people who reported higher expert comparisons, those who had lower global comparison ratings thought it was more important to change their behavior than those with higher global comparison ratings. 


\section{References}

Ajzen, I. (1991). The theory of planned behavior. Organizational Behavior and Human Decision Processes, 50, 179-211. https://doi.org/10.1016/0749-5978(91)90020-T

Albarracin, D., Johnson, B. T., Fishbein, M., \& Muellerleile, P. A. (2001). Theories of reasoned action and planned behavior as models of condom use: a meta-analysis. Psychological Bulletin, 127, 142-161. doi:10.1037/0033-2909.127.1.142

Alicke, M. D., Zell, E., \& Bloom, D. L. (2010). Mere categorization and the frog-pond effect. Psychological Science, 21, 174-177. https://doi.org/10.1177/0956797609357718

Bertholet, N., Gaume, J., Faouzi, M., Gmel, G., \& Daeppen, J. B. (2012). Predictive value of readiness, importance, and confidence in ability to change drinking and smoking. $B M C$ Public Health, 12(1), 708.

Blanchard, C. M., Fisher, J., Sparling, P. B., Shanks, T. H., Nehl, E., Rhodes, R. E., ... \& Baker, F. (2009a). Understanding adherence to 5 servings of fruits and vegetables per day: a theory of planned behavior perspective. Journal of Nutrition Education and Behavior, 41, 3-10. https://doi.org/10.1016/j.jneb.2007.12.006

Blanchard, C. M., Kupperman, J., Sparling, P. B., Nehl, E., Rhodes, R. E., Courneya, K. S., \& Baker, F. (2009b). Do ethnicity and gender matter when using the theory of planned behavior to understand fruit and vegetable consumption?. Appetite, 52, 15-20. https://doi.org/10.1016/j.appet.2008.07.001

Bruchmann, K., \& Evans, A. T. (2013). Abstract mind-sets and social comparison: When global comparisons matter. Social Psychological and Personality Science, 4, 427-433. https://doi.org/10.1177/1948550612464661

Buckingham, J. T., \& Alicke, M. D. (2002). The influence of individual versus aggregate social comparison and the presence of others on self-evaluations. Journal of Personality and 
Social Psychology, 83, 1117-1130. http://dx.doi.org/10.1037/0022-3514.83.5.1117

Burke, B. L., Arkowitz, H., \& Menchola, M. (2003). The efficacy of motivational interviewing: A meta-analysis of controlled clinical trials. Journal of Consulting and Clinical Psychology, 71, 843-861. https://doi.org/10.1037/0022-006X.71.5.843

Carver, C. S., \& Scheier, M. F. (1999). Themes and issues in the self-regulation of behavior. In R. S. Wyer, Jr. (Ed.), Perspectives on behavioral self-regulation: Advances in social cognition, Vol. 12, pp. 1-105). Mahwah, NJ, US: Lawrence Erlbaum Associates Publishers.

Conner, M., \& Armitage, C. J. (1998). Extending the theory of planned behavior: A review and avenues for further research. Journal of Applied Social Psychology, 28, 1429-1464. https://doi.org/10.1111/j.1559-1816.1998.tb01685.x

Conner, M., Norman, P., \& Bell, R. (2002). The theory of planned behavior and healthy eating. Health Psychology, 21, 194-201. https://doi.org/10.1037/0278-6133.21.2.194

Courneya, K. S., \& McAuley, E. (1995). Cognitive mediators of the social influence-exercise adherence relationship: A test of the theory of planned behavior. Journal of Behavioral Medicine, 18(5), 499-515.

Cummings, K. M., Jette, A. M., Brock, B. M., \& Haefner, D. P. (1979). Psychosocial determinants of immunization behavior in a swine influenza campaign. Medical Care, 17(6) 639-649.

DiClemente, C. C. \& Velasquez, M. W. (2002). Motivational Interviewing and the stages of change. In W.R. Miller and S. Rollnick (Eds.), Motivational Interviewing: Preparing people for change. (2nd ed., pp. 217-250). New York: Guilford Press.

Dillard, A. J., Ubel, P. A., Smith, D. M., Zikmund-Fisher, B. J., Nair, V., Derry, H. A., ... \& Fagerlin, A. (2011). The distinct role of comparative risk perceptions in a breast cancer 
prevention program. Annals of Behavioral Medicine, 42, 262-268.

https://doi.org/10.1007/s12160-011-9287-8

Dunning, D., Heath, C., \& Suls, J. M. (2004). Flawed self-assessment: Implications for health, education, and the workplace. Psychological Science in the Public Interest, 5, 69-106. https://doi.org/10.1111/j.1529-1006.2004.00018.x

Fagerlin, A., Zikmund-Fisher, B. J., \& Ubel, P. A. (2007). 'If I'm better than average, then I'm ok?': Comparative information influences beliefs about risk and benefits. Patient Education and Counseling, 69, 140-144. https://doi.org/10.1016/j.pec.2007.08.008

Ferrini, R. L., Edelstein, S. L., \& Barrett-Connor, E. (1994). Factors associated with health behavior change among residents 50 to 96 years of age in Rancho Bernardo, California. American Journal of Preventive Medicine, 10, 26-

30. https://doi.org/10.1016/S0749-3797(18)30643-3

Festinger, L. (1954). A theory of social comparison processes. Human Relations, 7, 117-140. https://doi.org/10.1177/001872675400700202

Fishbein, M., \& Ajzen, I. (2011). Predicting and changing behavior: The reasoned action approach. New York, NY: Psychology Press.

Flugstad, A. R., \& Windschitl, P. D. (2003). The influence of reasons on interpretations of probability forecasts. Journal of Behavioral Decision Making, 16, 107-126. https://doi.org/10.1002/bdm.437

French, D. P., Wade, A. N., \& Farmer, A. J. (2013). Predicting self-care behaviours of patients with type 2 diabetes: the importance of beliefs about behaviour, not just beliefs about illness. Journal of Psychosomatic Research, 74, 327-333. https://doi.org/10.1016/j.jpsychores.2012.12.008

Garson, G. D. (2012). Testing statistical assumptions. Asheboro, NC: Statistical Associates 
Publishing.

Gerber, J. P., Wheeler, L., \& Suls, J. (2018). A social comparison theory meta-analysis 60+ years on. Psychological Bulletin, 144, 177-197. http://dx.doi.org/10.1037/bul0000127

Gibbons, F. X., \& Gerrard, M. (1997). Health images and their effects on health behavior. In B. P. Buunk \& F. X. Gibbons (Eds.), Health, Coping, and Well-being: Perspectives from Social Comparison Theory (pp. 63-94). Mahwah, NJ, US: Lawrence Erlbaum Associates Publishers.

Gray, J. B., \& Harrington, N. G. (2011). Narrative and framing: A test of an integrated message strategy in the exercise context. Journal of Health Communication, 16, 264-281. https://doi.org/10.1080/10810730.2010.529490

Hagger, M. S., Chatzisarantis, N. L.D., \& Biddle, S. J.H. (2002). A meta-analytic review of the theories of reasoned action and planned behavior in physical activity: Predictive validity and the contribution of additional variables. Journal of Sport \& Exercise Psychology, 24(1), 3-32. https://doi.org/10.1123/jsep.24.1.3

Harris, P., Sparks, P., \& Raats, M. (2002). Theoretical and applied issues in the provision of absolute and comparative risk information. Risk, Decision and Policy, 7, 153-163. https://doi.org/10.1017/S1357530902000583

Hausenblas, H. A., Carron, A. V., \& Mack, D. E. (1997). Application of the theories of reasoned action and planned behavior to exercise behavior: A meta-analysis. Journal of Sport \& Exercise Psychology, 19(1), 36-51.

Hay, J. L., Ramos, M., Li, Y., Holland, S., Brennessel, D., \& Kemeny, M. M. (2016). Deliberative and intuitive risk perceptions as predictors of colorectal cancer screening over time. Journal of Behavioral Medicine, 39, 65-74. https://doi.org/10.1007/s10865015-9667-9 
Janssen, E., van Osch, L., de Vries, H., \& Lechner, L. (2011). Measuring risk perceptions of skin cancer: Reliability and validity of different operationalizations. British Journal of Health Psychology, 16, 92-112. https://doi.org/10.1348/135910710X514120

Jemmott, J. B., Ditto, P. H., \& Croyle, R. T. (1986). Judging health status: Effects of perceived prevalence and personal relevance. Journal of Personality and Social Psychology, 50, 899-905. doi:10.1037/0022-3514.50.5.899

King, T. K., Marcus, B. H., Pinto, B. M., Emmons, K. M., \& Abrams, D. B. (1996). Cognitivebehavioral mediators of changing multiple behaviors: smoking and a sedentary lifestyle. Preventive Medicine, 25(6), 684-691.

Klein, W. M. (1997). Objective standards are not enough: affective, self-evaluative, and behavioral responses to social comparison information. Journal of Personality and Social Psychology, 72(4), 763-774.

Klein, W. M. (2002). Comparative risk estimates relative to the average peer predict behavioral intentions and concern about absolute risk. Risk, Decision and Policy, 7, 193-202. https://doi.org/10.1017/S1357530902000613

Klein, W. M. (2003). Self-prescriptive, perceived, and actual attention to comparative risk information. Psychology and Health, 18, 625-643. https://doi.org/10.1080/0887044031000118465

Knowlden, A. P., Sharma, M., \& Bernard, A. L. (2012). A theory of planned behavior research model for predicting the sleep intentions and behaviors of undergraduate college students. The Journal of Primary Prevention, 33, 19-31. DOI: 10.1007/s10935-012-0263-2

LaBrie, J. W., Quinlan, T., Schiffman, J. E., \& Earleywine, M. E. (2005). Performance of alcohol and safer sex change rulers compared with readiness to change questionnaires. Psychology of Addictive Behaviors, 19, 112. https://doi.org/10.1037/0893-164X.19.1.112 
Lao, H. C., Tao, V. Y., \& Wu, A. M. (2016). Theory of planned behaviour and healthy sleep of college students. Australian Journal of Psychology, 68, 20-28. https://doi.org/10.1111/ajpy.12094

Lapinski, M. K., \& Rimal, R. N. (2005). An explication of social norms. Communication Theory, 15, 127-147. https://doi.org/10.1111/j.1468-2885.2005.tb00329.x

Larson, N., \& Story, M. (2009). A review of environmental influences on food choices. Annals of Behavioral Medicine, 38, s56-s73. DOI: 10.1007/s12160-009-9120-9

Lee, I. A., \& Preacher, K. J. (2013). Calculation for the test of the difference between two dependent correlations with one variable in common [Computer software]. Available from http://quantpsy.org.

Locke, K. D. (2007). Personalized and generalized comparisons: Causes and consequences of variations in the focus of social comparisons. Personality and Social Psychology Bulletin, 33, 213-225. https://doi.org/10.1177/0146167206293492

Mahler, H. I. (2018). The relative role of cognitive and emotional reactions in mediating the effects of a social comparison sun protection intervention. Psychology \& Health, 33, 235257. https://doi.org/10.1080/08870446.2017.1310860

Maltby, J., Wood, A. M., Vlaev, I., Taylor, M. J., \& Brown, G. D. (2012). Contextual effects on the perceived health benefits of exercise: The exercise rank hypothesis. Journal of Sport and Exercise Psychology, 34, 828-841. https://doi.org/10.1123/jsep.34.6.828

Manning, M. (2009). The effects of subjective norms on behaviour in the theory of planned behaviour: A meta-analysis. British Journal of Social Psychology, 48, 649-705. https://doi.org/10.1348/014466608X393136

Marshall, S. J., \& Biddle, S. J. (2001). The transtheoretical model of behavior change: a meta- 
analysis of applications to physical activity and exercise. Annals of Behavioral Medicine, 23(4), 229-246.

Michie, S., Whittington, C., Hamoudi, Z., Zarnani, F., Tober, G., \& West, R. (2012). Identification of behaviour change techniques to reduce excessive alcohol consumption. Addiction, 107, 1431-1440. DOI: 10.1111/j.1360-0443.2012.03845.x

Miller, W. R., \& Johnson, W. R. (2008). A natural language screening measure for motivation to change. Addictive Behaviors, 33, 1177-1182. https://doi.org/10.1016/j.addbeh.2008.04.018

Miller, W. R., \& Rollnick, S. (2002). Motivational interviewing: Preparing people for change (2nd ed.). New York: Guilford Press.

Miller, W. R., \& Rollnick, S. (2009). Ten things that motivational interviewing is not. Behavioural and Cognitive Psychotherapy, 37, 129-140. https://doi.org/10.1017/S1352465809005128

Mussweiler, T., \& Rüter, K. (2003). What friends are for! The use of routine standards in social comparison. Journal of Personality and Social Psychology, 85, 467-481. http://dx.doi.org/10.1037/0022-3514.85.3.467

Neighbors, C., Larimer, M. E., \& Lewis, M. A. (2004). Targeting misperceptions of descriptive drinking norms: Efficacy of a computer-delivered personalized normative feedback intervention. Journal of Consulting and Clinical Psychology, 72(3), 434-447. http://dx.doi.org/10.1037/0022-006X.72.3.434

Park, C. L., \& Gaffey, A. E. (2007). Relationships between psychosocial factors and health behavior change in cancer survivors: An integrative review. Annals of Behavioral Medicine, 34(2), 115-134. https://doi.org/10.1007/BF02872667

Portnoy, D. B., Kaufman, A. R., Klein, W. M., Doyle, T. A., \& De Groot, M. (2014). Cognitive 
COMPARISONS AND CHANGE

and affective perceptions of vulnerability as predictors of exercise intentions among people with type 2 diabetes. Journal of Risk Research, 17, 177-193.

https://doi.org/10.1080/13669877.2013.794153

Priebe, C. S., \& Spink, K. S. (2011). When in Rome: Descriptive norms and physical activity. Psychology of Sport and Exercise, 12, 93-98.

https://doi.org/10.1016/j.psychsport.2010.09.001

Prochaska, J. J., Velicer, W. F., Prochaska, J. O., Delucchi, K., \& Hall, S. M. (2006). Comparing intervention outcomes in smokers treated for single versus multiple behavioral risks. Health Psychology, 25, 380-388. doi:10.1037/0278-6133.25.3.380

Prochaska, J. O., DiClemente, C. C., \& Norcross, J. C. (1992). In search of the structure of change. In Self Change (pp. 87- 114). New York: Springer. https://doi.org/10.1007/978$1-4612-2922-3+5$

Prochaska, J. O., Redding, C. A., \& Evers, K. E. (2015). The transtheoretical model and stages of change. In K. Glanz, B.K. Rimer, \& K. Viswanath (Eds.), Health behavior: Theory, research, and practice (pp. 125-148). San Francisco, CA: Jossey-Bass.

Prochaska, J. O., \& Velicer, W. F. (1997). The transtheoretical model of health behavior change. American Journal of Health Promotion, 12, 38-48. DOI: 10.4278/0890-117112.1 .38

Renner, B., \& Reuter, T. (2012). Predicting vaccination using numerical and affective risk perceptions: the case of A/H1N1 influenza. Vaccine, 30, 7019-7026. https://doi.org/10.1016/j.vaccine.2012.09.064

Rimal, R. N., \& Real, K. (2005). How behaviors are influenced by perceived norms: A test of the theory of normative social behavior. Communication Research, 32, 389-414. https://doi.org/10.1177/0093650205275385 
Rollnick, S. (1998). Readiness, importance, and confidence: Critical conditions of change in $\mathrm{t}$ reatment. In W. R. Miller \& N. Heather (Eds.), Applied Clinical Psychology. Treating Addictive Behaviors (p. 49-60). Plenum Press.

Rollnick, S., Mason, P., \& Butler, C. (1999). Health Behavior Change: A Guide for Practitioners. Elsevier Health Sciences. London, United Kingdom: Churchill Livingstone

Rose, J. P. (2010). Are direct or indirect measures of comparative risk better predictors of concern and behavioural intentions?. Psychology and Health, 25, 149-165. https://doi.org/10.1080/08870440802340164

Schönbrodt, F. D., \& Perugini, M. (2013). At what sample size do correlations stabilize?. Journal of Research in Personality, 47, 609-612. https://doi.org/10.1016/j.jrp.2013.05.009

Schwarzer, R. (2001). Social-cognitive factors in changing health-related behaviors. Current Directions in Psychological Science, 10, 47-51. https://doi.org/10.1111/1467-8721.00112 Sheeran, P., Maki, A., Montanaro, E., Avishai-Yitshak, A., Bryan, A., Klein, W. M., ... \& Rothman, A. J. (2016). The impact of changing attitudes, norms, and self-efficacy on health-related intentions and behavior: A meta-analysis. Health Psychology, 35, 1178 1188. http://dx.doi.org/10.1037/hea0000387

Sproesser, G., Klusmann, V., Schupp, H. T., \& Renner, B. (2015). Comparative optimism about healthy eating. Appetite, 90, 212-218. https://doi.org/10.1016/j.appet.2015.03.008

Stanton, A. L., Danoff-Burg, S., Cameron, C. L., Snider, P. R., \& Kirk, S. B. (1999). Social comparison and adjustment to breast cancer: An experimental examination of upward affiliation and downward evaluation. Health Psychology, 18, 151-158. doi:10.1037/02786133.18 .2 .151

Tabachnick, B. G., \& Fidell, L. S. (2007). Using multivariate statistics. Allyn \& Bacon/Pearson 
Education.

Tagler, M. J., Stanko, K. A., \& Forbey, J. D. (2017). Predicting sleep hygiene: A reasoned action approach. Journal of Applied Social Psychology, 47, 3-12. https://doi.org/10.1111/jasp.12411

Weinstein, N. D. (1999). What does it mean to understand a risk? Evaluating risk comprehension. JNCI Monographs, 1999, 15-20. DOI:

10.1093/oxfordjournals.jncimonographs.a024192

Van Leer, E., Hapner, E. R., \& Connor, N. P. (2008). Transtheoretical model of health behavior change applied to voice therapy. Journal of Voice, 22, 688-698. https://doi.org/10.1016/j.jvoice.2007.01.011

Williams, E. C., Horton, N. J., Samet, J. H., \& Saitz, R. (2007). Do brief measures of readiness to change predict alcohol consumption and consequences in primary care patients with unhealthy alcohol use?. Alcoholism: Clinical and Experimental Research, 31, 428-435. https://doi.org/10.1111/j.1530-0277.2006.00324.X

Yun, D., \& Silk, K. J. (2011). Social norms, self-identity, and attention to social comparison information in the context of exercise and healthy diet behavior. Health Communication, 26, 275-285. https://doi.org/10.1080/10410236.2010.549814

Zell, E., \& Alicke, M. D. (2009). Contextual neglect, self-evaluation, and the frog-pond effect. Journal of Personality and Social Psychology, 97, 467-482. doi:10.1037/a0015453

Zell, E., \& Alicke, M. D. (2010). The local dominance effect in self-evaluation: Evidence and explanations. Personality and Social Psychology Review, 14, 368-384. https://doi.org/10.1177/1088868310366144

Zell, E., \& Alicke, M. D. (2013). Local dominance in health risk perception. Psychology \& Health, 28, 469-476. https://doi.org/10.1080/08870446.2012.742529 
